\title{
Study on Supporting Technology for Mechanized Construction of High Speed Railway Tunnel
}

\author{
Jun GAO \\ Civil engineering department \\ Tsinghua University \\ Beijing, China \\ Policegaojun@163.com
}

\author{
Xiao LIN \\ Railway Consultants Group Co.Ltd \\ Beijing, China \\ 1003296988@qq.com
}

\begin{abstract}
In order to improve the construction and management level of tunnel comprehensive mechanization, from the improvement of tunnel construction efficiency, select scientific and reasonable construction technology, from the construction technology and mechanized supporting, analyze the development status of equipment selection, tooling, technology and management related technology, and put forward the supporting principles, construction operation, and safeguard measures of the mechanized tunnel construction equipment. It was verified during the on-site implementation. The management and application of railway construction mechanization have been innovated.
\end{abstract}

Keywords-high speed railway tunnel; Mechanization Construction matching; Technology research

\section{INTRODUCTION}

With the development of the times, people have more and more requirements for the use of railway, the scale of "eight vertical and eight" high-speed railway is developing rapidly. In such a development background, mechanized construction is the basis for improving the quality and progress of the project. Combining with some practical construction cases, this paper analyzes the advantages and disadvantages of mechanized construction, especially the supporting scheme of the construction sequence of tunnel excavation and support frame construction in detail. The purpose is to help the current tunnel construction technology can keep up with the trend of the times, can promote the relevant construction experience, the project will be analyzed below, so as to study the actual supporting technology of mechanized construction.

\section{GENERAL SITUATION OF THE PROJECT}

This research selects the full length of $41.27 \mathrm{~km}$, through Sichuan area, so the geological conditions around the railway line is relatively complex, the karst geology is particularly numerous, there are many problems, such as cement outburst and ground collapse, etc., the number of tunnel involved is 14 , total length is 21.21 , the proportion of tunnel is $51.3 \%$, the total length of the tunnel is large, the risk factors are high, so it is convenient to adopt mechanized construction. The main tunnel is no 1 , the total length is 1900 , the maximum depth is $345 \mathrm{~m}$, the surrounding rock is mainly II and III, and the way of tunneling is unique. The longest tunnel is no 2 tunnel, the length reaches 6,550 , the maximum burial depth is $690 \mathrm{~m}$, and the seven of the surrounding rock become grade ii and grade iii materials, and the operation faces are mostly imported and exported. The larger problem is the bad lava geology, all of the secondary risk tunnel, there is a greater risk of security [1].

\section{TYPE SELECTION OF MECHANICAL EQUIPMENT AND ITS COROLLARY}

\section{A. Considerations for Equipment Selection}

In the selection of relevant mechanical equipment, and the process of matching process, the construction time of the tunnel project, the construction quality of the later stage and the actual safety issues are included in the scope of consideration. The selection of these machines and processes will require a few points to be taken into account:

- Construction programme: The selection of mechanical equipment has a very important influence on the construction scheme. Taking into account the geological problems and the practical conditions of the construction, the general construction scheme can be determined by comparing various modes: the drilling and blasting method construction is the traditional auxiliary method, and the mechanized construction method is adopted in the construction process, with the trackless Assemble in the hole and the track in the way of transportation; The excavation is based on the whole section method, and the construction method of short steps is adopted in some areas. The secondary lining adopts the whole section of the whole hydraulic steel mold lining trolley; mode of transportation in the tunnel is carried out under the circumstances of the track. In the process of selecting machinery to be matched with the scheme [2].

- In most cases, the higher the mechanization of construction, the better the construction quality, the construction cycle can be greatly shortened, so in the construction cycle requirements, the need to select a number of high performance equipment, and the actual quality of equipment to meet the requirements, the actual use of various equipment need to cooperate to prevent accidents, resulting in the production of 
equipment can not fully function. The tunnel requirements must be through within 20 months, the depth of excavation must reach more than 320 meters, and then further construction [3].

- The length of the tunnel is large, so the early consumption of funds, the use of large machinery can fully play a role, evaluation of the cost of the project can be appropriately reduced, is a cost-effective way; On the contrary, the length of the tunnel is small, the use of some large machinery, the cost is too large, and the transportation of equipment and so on, the cost of the average amount of work will be too high, this way is not appropriate. Therefore, from the economic point of view, we should consider the investment and production, and select the construction machinery according to the actual quantities. The no 2 tunnel is a long tunnel, with a large scale, the investment of the mechanical process before and after construction is about $40 \mathrm{~m}$ yuan, accounting for about one fifth of the total investment of the tunnel.

\section{ENVIRONMENTAL PROTECTION AND OCCUPATIONAL HEALTH REQUIREMENTS}

The air pollution in the tunnel is mainly from the dust, harmful gas and waste gas produced by blasting. For the tunnel ventilation, the long distance causes the difficulty of smoke extraction, so the electrical equipment should be used as far as possible, and the use of internal combustion equipment, as well as high-power ventilation equipment, should be avoided to improve the working environment and ensure the health of the operators. In addition, the appropriate reduction of equipment noise pollution should also be considered [4].

\section{CURRENT CONSTRUCTION STATUS OF DRILLING AND BLASTING METHOD IN CHINA}

The drilling and blasting method is the main construction method of the long tunnel in China, it has a strong flexibility, the early investment is relatively small, the adaptability is extremely strong, so the scope of use in the construction process in our country is wide. At present, the concrete construction equipment and process configuration of the domestic tunnel drilling and blasting method are as follows.

\section{A. Geological forecasting equipment}

Geological prediction is generally used in the domestic geological drilling machine, some of the better construction team also use imported geological drilling rig.

\section{B. Dredging equipment}

During the construction process, the main equipment will be electric air compressor, drilling platform, manual portable pneumatic drill and other practical equipment and machinery. The structure of the hole rack is relatively simple, but the biggest shortage is that the mobile is not convenient, and it needs to be used at the same time with other equipment, and the positioning of the platform is difficult; All equipment is combined with welding technology, so after the site removal, can not be used in the later period, height also limits the possibility of multifunctional operation, can only be used in a section tunnel excavation; When installing the centering, a large number of labor force is required to migrate. In the condition that the surrounding rock geological quality is qualified, some drilling jumbo is used to carry out the operation, and the ballast equipment needs to be combined with the large automobile.

\section{Initial support equipment}

The spray and shotcrete work is usually small spray wet equipment, in the long tunnel often used the larger type of manipulator, is the combination of artificial and mechanical construction process; Usually, the manual portable pneumatic drill or rock drilling jumbo is used for anchor construction, and the anchor trolley is generally not used.

\section{Inverted arch equipment}

The standard steel formwork and the common equipment and means for the implementation of the inverted arch trestle, and sometimes the construction equipment developed by the construction unit itself. The simple trestle is generally not equipped with protective equipment, so there is a large potential safety hazard, it also needs to use excavators when moving, so it is not particularly convenient.

\section{E. Anti - drainage equipment}

In the water drainage equipment, there is no professional waterproof machinery, waterproof plate laying is mostly simple laying, so the safety is not enough, there is a large safety hazard, often need to move the waterproof plate to the appropriate location to continue the construction; And in the opposite paved with $3 \mathrm{~m}$ wide waterproof board, the human resources consumption too much, and the time loss is too large, which is not conducive to the project.

\section{F. Secondary lining equipment}

The general use is the centralized mixing station to the concrete processing, the transportation is the concrete equipment, also includes the concrete transportation and the secondary piling technology. There is no maintenance trolley, the concrete maintenance measures are less, basically for nature conservation, so the actual effect is very poor.

\section{G. Enterprise development strategy requirements}

According to the long-term planning of the enterprise, considering the sustainable development of the enterprise, we must pay attention to the technological progress of the enterprise. The ability of technical equipment is one of the important symbols. With the help of large-scale projects, improve the enterprise equipment capacity, can not only accelerate the project progress, but also create the reputation of the enterprise, establish the corporate image, can also promote the progress of the whole industry. Of course, this should be combined with the existing equipment conditions, economic conditions, technical level and other factors to consider. 


\section{TECHNICAL SCHEME OF TUNNEL MECHANIZATION SUPPORTING CONSTRUCTION}

\section{A. Principles of mechanized equipment configuration}

In the tunnel construction project, the principle of mechanization equipment should be considered: advanced, efficient, reasonable, and at the same time capacity needs to meet the minimum requirements and quantity of production, each process can be coordinated with each other, so as to achieve the actual construction effect. According to the actual required degree of mechanization to match the corresponding scheme, the degree of mechanization of the division of the basis mainly contains the following points: production level, production capacity, and the level of surrounding rock. If the surrounding rock reaches grade iii, the specific supporting indicators are as follows: level I mechanization of $170 \mathrm{~m} /$ month, $140 \sim 170 \mathrm{~m} /$ month for level ii mechanization, and $140 \mathrm{~m} /$ month for level III mechanization. The surrounding rock of grade iii above shall be constructed with full section; the surrounding rock of the grade adopts the step construction method, and for other rock conditions, the concrete way of construction is not taken into account for the time being. The car is in the process of transporting it; the role of excavation of the tunnel needs to be managed in accordance with the actual construction capacity of 1.2 times [5].

\section{B. Configuration scheme of mechanized construction equipment}

The tunnel mechanization comprehensive system needs to follow the following requirements and standards: to set up some high power ventilation equipment such as geological alarm; The excavation operation line of the three - arm drilling jumbo can be properly configured; The use of some large tonnage loading operation lines; Configure the appropriate waterproof plate and welding auxiliary equipment; The lining operation line shall be composed of the concrete supply equipment and the hydraulic formwork trolley; The trench construction operation line shall be composed of groove movable formwork and concrete transport vehicle. Finally, the whole mechanized construction process of the tunnel is reached [6].

\section{MECHANIZATION CONSTRUCTION TECHNOLOGY OPTIMIZATION}

\section{A. Optimization of slotting scheme}

The blasting of hard rock tunnel is carried out quickly, and the optimization of cutting scheme is very important. The optimization of the cutting scheme can greatly improve the utilization rate of the hole, and save a large amount of explosive resources. On the contrary, if the cut is not suitable, a large number of explosives blasting will only "crush" the rock, and directly lead to uneven surface of the face, leading to the next blasting will be a large shortage, for the actual size can not be better control. After screening, we will select the double wedge cutting scheme. The actual depth of the first row of cutting guns will generally reach $4.5 \mathrm{~m}$, and the actual depth of the second row of cutting guns is generally $6.0 \mathrm{~m}$. Using the first blasting hole in the Squint slot to carry out the next step in the blasting technology, so as to quickly roll out the central part of the rock mass, and then blow up the second row of holes, the second row of the depth is $1.5 \mathrm{~m}$ deep relative to the first row of holes, and the fragmentation role needs to be appropriately added, thereby creating a larger space for the blasting engineering.

\section{B. Configuration of construction machinery equipment}

In the process of configuration, the mechanical equipment needs to put the technical and performance in the first place, while in the process of meeting the above conditions, the principle of a slight technical surplus needs to be guaranteed. According to the basic principle of car configuration, excavation and loading shall be formed as a running water. The basic requirements of mechanical configuration are: on the one hand, in order to ensure the quality and requirements of the construction, the capacity of the larger capacity of the slag loading machine, the capacity of the dump truck also needs to be satisfied. The equipment capacity used in the equipment must also be larger than the actual trial production requirements, and the storage capacity of the equipment must be adequate; the same kind of mechanical equipment is the best unified use the same manufacturer's equipment, convenient for the later equipment maintenance, to ensure the actual use of machinery.

\section{Refined management, optimization process}

In the course of the excavation, a comprehensive multifunctional operation table is used in the excavation process, and a pneumatic rock drill is used. In the actual excavation process, the non-electric millisecond detonators, and the emulsion explosive are generally used to open detonation, and the whole section is usually formed at one time. In order to do the rapid construction of the tunnel, first of all, we should guarantee the following work items, namely the excavation of the guide pit, the transportation in the tunnel and the seamless connection of the later process. In the problem of slag - tapping, the quality of the slag will play a key role in the speed of the whole project. After blasting, it is necessary to use the loader to conduct unified management of the flying slag stone, and then install the backhoe loader for the backhoe loader, and generally follow the transportation of GOLD PRINCE dump truck. The slag shall be transported to the mouth of the hole for a unified treatment. generally, the into shall be $4.0 \mathrm{~m}$, which shall be Pomace Draining with the quantity of 40 - 45 vehicles, and the average time of each cycle shall be 4-5 hours. In the initial aspect, because the surrounding rock has a certain effect on surrounding support, for most surrounding rock, the supporting function of the excavation face generally plays a supporting role to the surrounding three - action holes. In the actual construction process, the excavation face is often adopted to ensure the distance between the excavation face and the support equipment, so that the excavation and support procedures are carried out at the same time to reduce the excavation time. 


\section{CONCLUSION}

With the rapid development of economy, people demand more and more use of railway in such a development background, mechanized construction is the basis for improving the quality and progress of the project. Combining with some actual construction cases, this paper analyzes the advantages and disadvantages of mechanized construction, and helps the current tunnel construction technology can meet the actual production needs.

\section{REFERENCES}

[1] Gao shaoqiang, suixiuzhi. Tunnel engineering [M]. Beijing: China railway press, 2015.

[2] Yushuhan, dumoyuan. Tunnel construction [M]. Beijing: people's transportation press, 2014.

[3] Deng Qing ping. Summary of tunnel construction technology of Linchiang station in Chongqing [J]. tunnel construction, 2014, 24 (2): 36 -39 .

[4] RS. construction points of tunnel engineering [M]. Beijing: people's transportation press, 2015 .

[5] Uo haibo. The application of mechanized construction in the construction of high - speed railway tunnel [J]. Shanxi building, 2016, 09: 144-146.

[6] Fang jun wave. research on mechanized supporting technology and equipment for long tunnel construction [J]. high - speed railway technology, 2015, 03: $17-22$. 